\section{RMD Open}

Rheumatic \&

Musculoskeletal Diseases

\title{
Health technology assessment: a framework
}

\author{
Manuela Joore, ${ }^{1}$ Sabine Grimm (D), ${ }^{1}$ Annelies Boonen, ${ }^{2}$ Maarten de Wit (D), ${ }^{3}$ \\ Francis Guillemin (1D, ${ }^{4,5}$ Bruno Fautrel (iD) 6,7
}

To cite: Joore M, Grimm S, Boonen A, et al. Health technology assessment: a framework. RMD Open 2020;6: e001289. doi:10.1136/ rmdopen-2020-001289

Received 24 April 2020 Revised 16 June 2020 Accepted 17 June 2020

\section{SLinked}

http://dx.doi.org/10.1136/ rmdopen-2020-001238

http://dx.doi.org/10.1136/ rmdopen-2020-001286

http://dx.doi.org/10.1136/ rmdopen-2020-001287

- http://dx.doi.org/10.1136/ rmdopen-2020-001288

Check for updates

(C) Author(s) (or their employer(s)) 2020. Re-use permitted under CC BY-NC. No commercial re-use. See rights and permissions. Published by BMJ.

For numbered affiliations see end of article.

Correspondence to

Sabine Grimm; sabine.grimm@ mumc.nl

\section{INTRODUCTION TO THE CONCEPT OF HEALTH TECHNOLOGY ASSESSMENT}

In a time where there is growing pressure on healthcare budgets, there is increased scrutiny of new health technologies, their effectiveness, safety and costs. ${ }^{1}$ It is in this context that Health Technology Assessment (HTA) has become increasingly important. The purpose of HTA is to provide policymakers with evidence to inform decision-making and develop guidance on the reimbursement and administration of new health technologies in a national healthcare system. As such, HTA is regarded as a bridge between research evidence and health policy. $^{2}$ HTA is a multidisciplinary process, encompassing diverse aspects such as medical, economic, organisational, social and ethical considerations. The term 'health technology' is used in its broader sense and, with it, we typically refer to any product or activity that is used to promote health in any way, for instance, by preventing or treating disease, improving rehabilitation, and long-term care. ${ }^{3}$

\section{ECONOMIC EVALUATION WITHIN HTA}

HTA can aid a national health system with making decisions on how to allocate the often limited healthcare funds to different health technologies. Healthcare systems are faced with many new and old health technologies and insufficient resources to fund all of these. The result is a concept known as 'opportunity cost', which describes the value of the achievable benefits forgone by funding one technology, which comes at the expense of another. HTA can help decide which health technologies best to fund. At its heart is often an economic evaluation that compares health technologies in terms of their costs, clinical effectiveness, side effects, impact on HRQoL, impact on organisations, among others.

\section{TYPES OF ECONOMIC EVALUATION}

There are different types of economic evaluation and they can be distinguished by the outcomes that are considered in each (table 1). ${ }^{4}$ Cost analysis studies consider the costs associated with the health technologies in question, with the objective to identify the one associated with the lowest costs. These are therefore also called cost-minimisation studies. They implicitly make the assumption that the health technologies under consideration are equivalent in terms of their benefits. Because this assumption is rarely justified, these are now rarely used, with the notable exceptions of burden of illness studies and budget impact analyses. The former are not

Table 1 Measurement of costs and consequences in economic evaluation

\begin{tabular}{|c|c|c|c|}
\hline $\begin{array}{l}\text { Type of economic } \\
\text { evaluation }\end{array}$ & $\begin{array}{l}\text { Consideration } \\
\text { of costs? }\end{array}$ & $\begin{array}{l}\text { Consideration of } \\
\text { conseqences? } \dagger\end{array}$ & Valuation of consequences? \\
\hline $\begin{array}{l}\text { Cost analysis: burden of } \\
\text { illness, budget impact* }\end{array}$ & Yes & No & None \\
\hline Cost-effectiveness analysis & Yes & Yes & $\begin{array}{l}\text { Natural units, for example, life- } \\
\text { years }\end{array}$ \\
\hline Cost-utility analysis & Yes & Yes & $\begin{array}{l}\text { Healthy years, for example, } \\
\text { quality-adjusted life-years }\end{array}$ \\
\hline Cost-benefit analysis & Yes & Yes & Monetary units \\
\hline
\end{tabular}

*Partial economic evaluation.

†Consequences include valuation of health outcomes, either expressed in utilities or in monetary terms. Adapted from Drummond et al. ${ }^{4}$ 
full economic evaluations because they do not compare alternatives. Instead, burden of illness studies aim to assess the cost of a disease to society. Budget impact analyses, on the other hand, are broader cost analyses that assess the financial impact of adopting a health technology over another in the healthcare system, taking into account the size of the population that would receive it. As such, it addresses the question of affordability, rather than that of value for money.

Cost-effectiveness analyses evaluate whether a new health technology provides value relative to other existing health technologies. To assess this, a comparison of costs and consequences (such as health outcomes) associated with all technologies in question is made. The outcomes are typically expressed in life-years gained when adopting a new technology compared with life-years gained with existing technologies.

Cost-utility analyses are essentially cost-effectiveness analyses in which gains in health-related quality of life (HRQoL) are considered and assessed. A commonly used measure of HRQoL is the quality-adjusted life-year (QALY). Cost-utility analyses commonly result in a relative measure of costs per QALY gained: the incremental cost-effectiveness ratio (ICER). The ICER is then compared to a threshold value below which a technology is deemed cost-effective use of resources, or, put more simply, value for money.

Finally, cost-benefit analyses evaluate both costs and consequences in monetary terms (ie, for example, in euros). For this, it is necessary to assign a monetary value to any consequences associated with the alternative health technologies.

\section{DESIGN OF AN ECONOMIC EVALUATION WITHIN HTA}

To design an economic evaluation within HTA, we ask a set of standard questions that, when addressed, form the scope of the study. These questions can be summarised under the acronym PICOTP: Population, Intervention, Comparators, Outcomes, Time horizon, Perspective. Under Population, we define the patient population that can potentially be helped with the new health technology. Precision is advised in terms of patients' treatment history, specific characteristics of the condition, age or any other patient characteristics that may play a role. Often, the definition of patients will be aligned with that of the technology's (planned) marketing authorisation. In Intervention, we specify not only which intervention but also the dosage, mode of administration and anything else that is relevant, in line with the marketing authorisation. The same level of precision is required in Comparators, where this should be provided for each potential comparator. Here it is advisable to be broad in the inclusion of comparators and not to discard any at this stage based on, for example, lack of evidence. In the definition of Outcomes, we consider anything that may be relevant to the patients with the condition in question, as well as the effects on costs, and the organisation. These are often defined in terms of health states or events that capture the patients' disease progression as well as any treatment effects, and to which costs and QALYs can be assigned. In Time horizon, we define the length of time for which the new technology will have an impact on costs and consequences. Typically, a patient lifetime horizon is used. Finally, the question of the Perspective defines whether the economic evaluation is conducted from a health service perspective, a societal perspective, or the perspective of an organisation, such as a hospital. The perspective is important as it determines which comparators and outcomes are to be included and what time horizon is appropriate.

\section{ANALYTICAL APPROACH TO ECONOMIC EVALUATION}

There are two commonly used approaches to economic evaluation: a trial-based approach versus a decisionanalytic modelling-based approach. ${ }^{5}$ In the trial-based approach, a trial provides most of the evidence necessary to inform the economic evaluation, that is, it covers the scope and is in line with the PICOTP. If this is a randomised controlled trial (RCT), this approach offers the advantage of high internal validity, that is, randomisation means that estimates of effectiveness and costs are relatively unbiased for that group of patients in that setting. However, there are drawbacks and these include, among others, that the RCT may not be generalisable to the population that is relevant to policy-makers and that trial follow-up may be shorter than the time horizon of interest, and indeed too short to capture all effects that a health technology can have on patients. An approach using decision-analytic modelling can address some of these issues, allowing for long-term prediction of outcomes, and consideration of uncertainty. However, this approach requires synthesis of different evidence sources, and as such may sacrifice on internal validity. ${ }^{6}$

\section{HTA IN DIFFERENT JURISDICTIONS}

Economic evaluation can help attain and sustain universal health coverage, also in the context of low- and middle-income countries. ${ }^{7}$ Use of HTA, normative choices and methodological guidelines can differ by country. ${ }^{78}$ There are some initiatives to harmonise the HTA landscape in terms of methods used, such as the International Network of Agencies for Health Technology Assessment. ${ }^{9}$ And indeed, it appears desirable that HTA be undertaken jointly between countries in some cases, for example, to enable price negotiations with pharmaceutical companies, which may be of particular concern in rheumatology where innovative and expensive treatments become available virtually every year. On the other hand, HTA needs to consider the local context to aid with local determination of health priorities. ${ }^{7}$

In conclusion, HTA can help provide evidence to inform decision-making and develop guidance on the 
reimbursement and administration of new health technologies, which can enable attain and sustain universal health coverage. The global HTA landscape is currently fragmented and initiatives to enable cooperation between HTA agencies, while empowering countries to set priorities of their own, are ongoing.

\section{Author affiliations}

${ }^{1}$ KEMTA, Maastricht University Medical Center, Maastricht, Netherlands

${ }^{2}$ Department of Internal Medicine, Division of Rheumatology, Maastricht University Medical Center, and the CAPHRI Research Institute Maastricht University, Maastricht, Netherlands

${ }^{3}$ Patient Research Partner, EULAR, Zaltbommel, Netherlands

${ }^{4}$ School of Public Health, Nancy, France

${ }^{5}$ CHRU-Nancy, Inserm, Université de Lorraine, CIC Epidémiologie clinique, Nancy, France

${ }^{6}$ Rheumatology, Assistance Publique-Hopitaux De Paris, Paris, France

${ }^{7}$ GRC08-IPLESP, UPMC Faculte De Medecine, Paris, France

Acknowledgements This manuscript was written in support of the preparation of the EULAR health economics in rheumatology course.

Contributors MJ and SG drafted this manuscript and $\mathrm{AB}, \mathrm{MdW}, \mathrm{FG}$ and $\mathrm{BF}$ provided their comments and approved the final manuscript.

Funding The authors have not declared a specific grant for this research from any funding agency in the public, commercial or not-for-profit sectors.

Competing interests None declared.

Patient consent for publication Not required.

Provenance and peer review Not commissioned; externally peer reviewed.

Data sharing statement There are no data in this work.

Open access This is an open access article distributed in accordance with the Creative Commons Attribution Non Commercial (CC BY-NC 4.0) license, which permits others to distribute, remix, adapt, build upon this work noncommercially, and license their derivative works on different terms, provided the original work is properly cited, appropriate credit is given, any changes made indicated, and the use is non-commercial. See: http://creativecommons. org/licenses/by-nc/4.0/.

ORCID iDs

Sabine Grimm http://orcid.org/0000-0002-2175-7999

Maarten de Wit http://orcid.org/0000-0002-8428-6354

Francis Guillemin http://orcid.org/0000-0002-9860-7024

Bruno Fautrel http://orcid.org/0000-0001-8845-4274

\section{REFERENCES}

1 European Network for Health Technology Assessment. EUnetHTA our history and governance 2020 [March 2020]. Available https:// eunethta.eu/about-eunethta/history-of-eunethta/ (accessed 5 March 2020).

2 World Health Organisation. Health technology assessment 2020 [March 2020]. Available https://www.who.int/medical_devices/assess ment/en/ (accessed 5 March 2020).

3 National Institute for Health Research. Health technology assessment 2020 [March 2020]. Available https://www.nihr.ac.uk/explore-nihr /funding-programmes/health-technology-assessment.htm (accessed 5 March 2020).

4 Drummond M, Sculpher M, Torrance G, et al. Methods for the economic evaluation of health care programmes, 4th edn. Drummond M, editor. Oxford: Oxford University Press. 2015.

5 Ramsey S, Willke R, Briggs A, et al. Good research practices for cost-effectiveness analysis alongside clinical trials: the ISPOR RCT-CEA task force report. Value Health 2005;8:521-33.

6 Sculpher M. Clinical trials provide essential evidence, but rarely offer a vehicle for cost-effectiveness analysis. Value Health 2015;18:141-2.

7 Chalkidou K, Li R, Culyer AJ, et al. Health technology assessment: global advocacy and local realities comment on "priority setting for universal health coverage: we need evidence-informed deliberative processes, not just more evidence on cost-effectiveness". Int J Health Policy Manag 2017;6:233-6.

8 Oortwijn W, Broos $\mathrm{P}$, Vondeling $\mathrm{H}$, et al. Mapping of health technology assessment in selected countries. Int J Technol Assess Health Care 2013;29:424-34.

9 INAHTA. The International Network of Agencies for Health Technology Assessment 2020 [June 2020]. Available http://www. inahta.org/ (accessed 15 June 2020). 